\title{
CARACTERIZAÇÃO MICROESTRUTURAL DE ESCÓRIA GRANULADA DE ACIARIA PARA FABRICAÇÃO DE PEÇAS DE CERÂMICA VERMELHA*
}

Kate Thayane Santos Bezerra ${ }^{1}$ Clara Giovana Souza Silva ${ }^{1}$ Geyna Evellyn Silva de Jesus ${ }^{1}$ Alisson Clay Rios da Silva ${ }^{2}$ Sérgio Neves Monteiro ${ }^{3}$ Verônica Scarpini Candido 4

\section{Resumo}

O conhecimento das características microestruturais de materiais utilizados como constituintes mássicos de cerâmica vermelha é de grande importância para a compreensão das propriedades das peças queimadas. Assim, este estudo tem por objetivo caracterizar microestruturalmente a escória granulada de aciaria proveniente de uma siderúrgica do estado do Pará visando a sua incorporação em argilas para produção de peças de cerâmica vermelha. O resíduo passou pela etapa de beneficiamento e, depois, foi realizada a difração de raios-X (DRX) e fluorescência de raios-X (FRX). Além disso, realizou-se também a análise morfológica por microscopia eletrônica de varredura (MEV). Os resultados mostraram que hematita, magnetita e wustita são as fases predominantes associadas aos óxidos de ferro. A análise química por FRX mostrou que o resíduo apresenta baixos teores de sílica (SiO2) e alumina (Al2O3), associados a elevados teores de óxidos de ferro e óxido de magnésio. Dessa forma, a caracterização da escória granulada de aciaria mostrou que esse resíduo apresenta-se como um potencial constituinte mássico cerâmico podendo contribuir para a formação de fase liquida durante o que acarretaria em melhoria das propriedades tecnológicas como absorção de água e resistência mecânica.

Palavras-chave: Caracterização; Cerâmica Vermelha; Escória Granulada de Aciaria.

\section{STEEL SLAG MICROSTRUCTURAL CHARACTERIZATION FOR PRODUCTION OF} RED CERAMICS

\section{Abstract}

This study aims to characterize the steel slag from a steel mill in the state of Pará, aiming at its incorporation into clays for tiles production. The residue passed through the processing step and X-ray diffraction (XRD) and X-ray fluorescence (XRD) were performed. The results showed that hematite, magnetite and wustite are the predominant phases. The chemical analysis by FRX showed that the residue presents low levels of silica (SiO2) and alumina (Al2O3) associated with high levels of iron oxide. Thus, the characterization of steel slag showed that this residue presents itself as a potential ceramic constituent and can contribute to the formation of liquid phase during which it would lead to improvement of technological properties such as water absorption and mechanical resistance.

Keywords: Steel Slag; Characterization; Red Ceramics; Tiles.

1 Graduanda em Engenharia de Materiais, Faculdade de Engenharia de Materiais, Universidade Federal do Pará (UFPA), Ananindeua-PA, Brasil.

2 Químico industrial, Doutor em Ciência dos Materiais, Professor Adjunto I, Faculdade de Engenharia de Materiais, Universidade Federal do Pará (UFPA), Ananindeua-PA, Brasil.

3 Engenheiro de Materiais, PhD em Engenharia e Ciência dos Materiais, Professor, Programa de Pós-graduação em Engenharia de Materiais/Departamento de Engenharia mecânica e Materiais, Instituto Militar de Engenharia (IME), Rio de Janeiro, Rio de Janeiro, Brasil.

4 Bióloga, Doutora em Ciência dos Materiais, Professora Adjunta I, Faculdade de Engenharia de Materiais, Universidade Federal do Pará (UFPA), Ananindeua-PA, Brasil.. 


\section{INTRODUÇÃO}

Cerâmicos são materiais inorgânicos formados, geralmente, por metais e ametais que estão ligados entre si por ligações predominantemente iônica e, eventualmente, algumas ligações covalentes [1]. Os materiais cerâmicos podem ser classificados como: materiais refratários, materiais de revestimento, isolantes térmicos, fritas e corantes, abrasivos, vidro cimento e cal, cerâmicas avançadas, cerâmica branca e cerâmica vermelha [2].

Dentre esses diversos tipos de cerâmica, a cerâmica vermelha possui grande importância no cenário nacional, pois é o ramo industrial que produz blocos, tijolos, telhas, argilas expandidas e pisos intertravados. Estima-se que o faturamento anual desse setor se aproxime de 18 bilhões de reais gerando cerca de 293 mil empregos diretos e 900 mil indiretos [3].

A indústria de cerâmica vermelha por muito tempo utilizou de métodos empíricos para a fabricação das peças. Devido a isso, problemas durante a secagem e a queima, problemas dimensionais e de resistência se tornaram comuns no processo produtivo [4-6]. Atualmente, observa-se que em muitas cerâmicas, há uma maior preocupação em formular composições que apresentem melhores parâmetros tecnológicos e há maior controle de qualidade do produto final. Essas mudanças no processo produtivo proporcionam maior economia de energia e maior lucro no produto final [7].

Para a produção das peças de cerâmica vermelha, são utilizados recursos não renováveis como argila e areia. Como as matérias-primas são materiais naturais, a dosagem errada ou a falta de algum mineral pode acarretar em peças com elevados percentuais de absorção de água e baixa resistência mecânica. Por esse motivo, a incorporação de resíduos sólidos tem se mostrado como uma alternativa viável para melhorar as propriedades tecnológicas das cerâmicas vermelhas e um destino final ambientalmente correto para esses materiais $[8,9]$.

Diversos são os tipos de resíduos que podem ser incorporados em massa argilosa para produção de peças de cerâmica vermelha e os resultados sobre as propriedades tecnológicas têm se mostrado positivos. PINHEIRO et al. (2008) [10] avaliaram o efeito da adição de resíduos provenientes da produção de papel em massa cerâmica vermelha e observaram que a adição de $10 \%$ em peso de resíduo provocou um aumento na absorção de água com consequente diminuição da resistência à flexão. Os autores concluíram que a adição de até $3 \%$ em peso de resíduo contribuiu para a diminuição da absorção e aumento da resistência.

A escória de aciaria é um resíduo de granulometria grosseira e rica em óxido de cálcio, gerado a partir da produção do aço. Sua utilização como constituinte mássico para produção de peças cerâmicas pode ser uma alternativa para seu descarte e para produção de peças com propriedades tecnológicas desejáveis. Assim, esse trabalho tem por objetivo realizar a caracterização microestrutural da escória granulada de aciaria para produção de peças de cerâmica vermelha.

\section{MATERIAIS E MÉTODOS}

A escória de aciaria foi obtida de uma siderúrgica localizada no estado do Pará e, após sua obtenção, o resíduo foi encaminhado à Usina de Materiais da Universidade Federal do Pará.

A escória foi seca em estufa de modelo DIMATE, à temperatura de $110{ }^{\circ} \mathrm{C}$ durante 24h. Após essa etapa o material foi conduzido para o moinho de bolas de 
modelo Work Index série 005, onde foi realizada a etapa de desagregação, por um período de 30 minutos.

Em seguida, o resíduo foi passado em peneira com abertura de 325 mesh e encaminhado para a análise mineralógica, química e morfológica. A difração de raios-X (DRX), foi realizada em amostras na forma de pó em difratômetro da Bruker, modelo D2- Phaser, operando a $30 \mathrm{kV}$ e $10 \mathrm{~mA}$ e com um comprimento de onda $\lambda \mathrm{CuK} \alpha=1,5406 \AA$. As amostras foram examinadas em um intervalo de $2 \theta$ entre 0 e $60^{\circ}$, a uma taxa de varredura de $8 \% \mathrm{~min}$.

A Fluorescência de raios-X (FRX) foi realizada utilizando o equipamento Axios Minerals da PANalytical.

\section{RESULTADOS} aciaria.

A tabela 1 apresenta o resultado da fluorescência de raios-x da escória de

Tabela 1. Composição química da escória de aciaria

\begin{tabular}{ll}
\multicolumn{2}{c}{ Escória de Aciaria } \\
Componente & $\begin{array}{c}\% \text { em } \\
\text { peso }\end{array}$ \\
\hline $\mathrm{SiO}_{2}$ & 10,70 \\
$\mathrm{Al}_{2} \mathrm{O}_{3}$ & 3,90 \\
$\mathrm{Fe}_{2} \mathrm{O}_{3}$ & 11,10 \\
$\mathrm{TiO}_{2}$ & 1,00 \\
$\mathrm{MnO}$ & 5,84 \\
$\mathrm{MgO}$ & 8,83 \\
$\mathrm{CaO}$ & 38,67 \\
$\mathrm{FeO}$ & 15,48 \\
$\mathrm{P}_{2} \mathrm{O}_{5}$ & 1,46 \\
\hline
\end{tabular}

Nota-se que a escória de aciaria apresenta elevados teores de óxidos de ferro. Esse resultado pode contribuir para conferir a cerâmica queimada a coloração avermelhada. As argilas encontradas no estado do Pará, geralmente, possuem baixos teores de óxidos de ferro o que confere as peças finais uma cor mais clara. Destaca-se também o baixo teor de sílica e alumina associado ao elevado teor de óxido de magnésio. O elevado percentual desse óxido pode contribuir para formação de fase líquida podendo contribuir para melhorar a resistência das peças queimadas.

A análise por difração de raios-X (DRX) da escória de aciaria está apresentada na figura 1. 


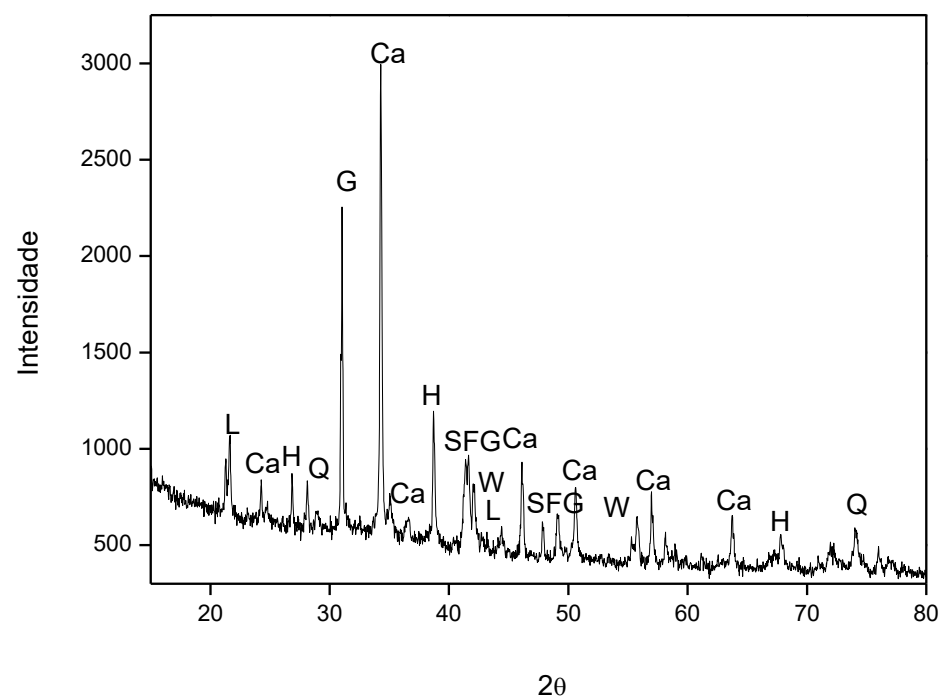

Figura 1. Difratograma de raios-x da escória de aciaria. Ca: calcita, SFG: silicato de ferro e magnésio,

G: gismondina, H: hematita M: magnetita, Q: quartzo, W: wustita, L: larnita.

A análise por difratometria de raios- $x$ da escória de aciaria revelou a presença de fases como a hematita, magnetita e wustita que estão associadas a compostos de ferro. Além dessas fases associadas a óxidos ferro, fases como calcita, quartzo, larnita gismondina e silicato de ferro e magnésio também foram observadas.

Devido à composição química complexa, vale ressaltar que podem existir outras fases cristalinas minoritárias ou compostos amorfos eu não são identificados no difratograma.

\section{CONCLUSÃO}

A caracterização da escória de aciaria forno revelou que o resíduo apresenta baixos teores de sílica e alumina associados a elevados teores de óxido e magnésio, o que pode contribuir para a formação de fase liquida durante a etapa da de queima. Além disso, notam-se elevados teores de óxido de cálcio que podem induzir a formação de patologias nas cerâmicas queimadas, por esse motivo, indica-se a incorporação de baixos teores desse resíduo. Destaca-se ainda que o resíduo é rico em óxidos de ferro o que pode contribuir para intensificar a cor avermelhada nas peças queimadas.

\section{REFERÊNCIAS}

1 WD Callister Jr. Ciência e Tecnologia de Materiais: uma introdução. 8 ed. Rio de Janeiro: Editora S.A. 2012, 705p.

2 ABECERAM - Associação Brasileira de Cerâmica - Disponível em: http://www.abceram.org.br/. Acessado em abril de 2016.

3 ANICER - Associação nacional da indústria cerâmica - Disponível em: http://portal.anicer.com.br/setor/. Acessado em abril de 2016.

4 CMF Vieira, ETA Souza, SN Monteiro. Efeito da incorporação de chamote no processamento e microestrutura de cerâmica vermelha. Cerâmica, 50, 254-260, 2004. 
5 FF Ripoli. A Utilização do Rejeito Industrial Cerâmico - Chamote - como Fator de Qualidade na Fabricação de Elementos Cerâmicos: um Estudo Experimental. Cerâmica. 1997; 43, 281-282.

6 GM Bustamante, JC Bressiani. A indústria cerâmica brasileira. Cerâmica Industrial. 2000; 5(3): 31-36.

7 IS Ramos, MG Alves, J Alexandre. Diagnóstico do Polo Cerâmico de Campos dos Goytacazes - RJ. Cerâmica Industrial, 2006; 11 (1): 28-32

8 CMF Vieira, SN Monteiro. Incorporation of solid wastes in red ceramics - an updated review. Revista Matéria. 2009; 14(3): 881 - 905.

9 VS Candido, RM Pinheiro, SN Monteiro, CMF Vieira. Desenvolvimento de adoquim cerâmico, com argilas cauliníticas, chamote e argilito. Cerâmica. 2013; 59, 310-316.

10 RM Pinheiro, CMF Vieira, RS Rodriguez, SN Monteiro. Reciclagem de resíduo proveniente da produção de papel em cerâmica vermelha. Rev. Matéria. 2008; 13 (1):220-227. 